\title{
"Manufacturing Life" in Real Work Processes? New Manufacturing Environments with Micro- and Nanorobotics
}

\author{
António Brandão Moniz (D) \\ Bettina-Johanna Krings ${ }^{(1)}$
}

Received: 18 June 2020 / Accepted: 25 November 2021 / Published online: 25 January 2022

(C) The Author(s) 2022

\begin{abstract}
The convergence of nano-, bio-, information, and cognitive sciences and technologies (NBIC) is advancing continuously in many societal spheres. This also applies to the manufacturing sector, where technological transformations in robotics push the boundaries of human-machine interaction (HMI). Here, current technological advances in micro- and nanomanufacturing are accompanied by new socioeconomic concepts for different sectors of the process industry. Although these developments are still ongoing, the blurring of the boundaries of HMI in processes at the micro- and nano- level can already be observed. According to the authors, these new socio-technical HMIs may lead to the development of new work environments, which can also have an impact on work organization. While there is still little empirical evidence, the following contribution focuses on the question whether the "manufacturing (or working) life" using enhancement practices pushes the boundaries of HMI and how these effects enable new modes of working in manufacturing.
\end{abstract}

A. B. Moniz $(\square)$

CICS.NOVA, Interdisciplinary Centre of Social Sciences, Faculty of Sciences and Technology, Universidade Nova de Lisboa, 2829-516 Caparica, Portugal

e-mail: abm@fct.unl.pt

\section{B.-J. Krings}

Institute for Technology Assessment and Systems

Analysis (ITAS), Karlsruhe Institute of Technology (KIT),

76133 Karlsruhe, Germany

e-mail: Bettina-johanna.krings@kit.edu
Issues of standardization, acceleration of processes, and order-oriented production become essential for technological innovation in this field. However, these trends tend to lead to a "manufacturing life" in work environments rather than to new modes of work in industry.

Keywords Emerging technologies $\cdot$ Robotics · Blurring boundaries of HMI - Modes of work at micro- and nanoscale

\section{Introduction}

The convergence of nano-, bio-, information, and cognitive sciences and technologies (NBIC) is continuously advancing in a wide range of work and social spheres. These technological advances have constantly changed the interrelation between "natural" and "artificial" material and have led to a blurring of the boundaries between humans and machines. The debate about the boundaries between humans and technology has been intense for decades [1, 2] and still seems an important topos today. This is also true for current NBIC developments, which probably will lead to a profound change in "our sense of being human - concerning its nature, capabilities, and limits" [3]. Transformation processes triggered by technologies such as molecular manipulation or the development of artifacts that can intervene in organic structures will thus result in radical changes 
in the meaning of life itself $[4,5]$. In this development towards a "manufacturing of life", the informatization of processes, new forms of standardization, and order-oriented production become essential conditions for socio-technological innovation $[3,6,7]$.

Interestingly, the blurring of boundaries can also be identified in classic environments of standardization and order-oriented production: in real manufacturing processes. Here, technical advances in micro- and nanomanufacturing environments with robots were accompanied by new industrial concepts in the last decade. At these size levels, products manufactured by such novel machines (nanorobots) are mostly found in the field of health devices such as tissues, nanoelectronics biosensors, molecular devices, and drug components. According to Nelson, Dong, and Arai, "nanorobotics is the study of robotics at the nanometer scale, and includes robots that are nanoscale in size, i.e., nanorobots, and large robots capable of manipulating objects that have nanometer dimensions with nanometer resolution, i.e., nano robotic manipulators" [8]. But molecular manipulation is also used in the field of additive manufacturing, especially for microelectronic products and specialized machines. In this way, converging NBIC technologies move from the laboratory to the shop floor. Microelectronics is important in the field of computer components such as microchips, wafers, devices for the Internet of Things (IoT), and sensors. Both products types cover a variety of industries and specific applications. At the same time, our daily life is filling up with new objects and devices with ever smaller components, such as laptops, smartphones, printers, watches, etc., manufactured by these industries. Especially in these contexts, a blurring of boundaries can be observed, both at the macrolevel (manufacturing of micro- and nanoproducts) and at the micro- and nano levels (application of the products manufactured). At both levels, human-machine interaction (HMI) involves new interfaces which are not yet clearly defined in all sectors of the process industry [9].

Today, HMI in the process industry is characterized by the use of sensors that control the increased accuracy of production flow, product components, and product quality. These sensors provide huge amounts of data and information about the manufacturing status, which are evaluated in control and management processes. The operators involved usually control production processes using this indirect information, but they also use data collected through direct information. Due to the high division of labor in production, their expertise, work experience, and feeling for the processes are only partially used and differ according to their tasks in the work processes [10-12].

HMI in micro- and nanomanufacturing seems even more indirect, as machine operators observe the manufacturing processes directly, but only through specialized microscopes and computers. The technologies "mediate" the work processes. Therefore, working on both scales requires, on the one hand, increased abstraction and simulation skills of the workers. On the other hand, the application of this type of technical tools and artifacts is associated with increased standardization of work processes [13].

Starting from these observations, this article focuses on the overall question: How do issues of manufacturing life influence real working models in manufacturing? Actually, socio-technical environments such as industrial robotics have a long tradition in the manufacturing sector. They are still organized by highly rationalistic work structures that are based on strict boundaries between humans and machines [14-16], even if such boundaries metaphorically take the form of fences in robotics cells. ${ }^{1}$ Robotic cells consider the integration of one, or more than one, robot and other machinery, buffers, local warehouses, conveyors, sensors, etc., and when they are operating in automatic modes at shop floors, it is needed to apply stationary fences for safety reasons. Recent developments make possible the use of virtual fences, maintaining the strict boundaries between machines and humans. Against this background, the article focuses on the question whether working with robotics on the micro- and nanoscale will push the boundaries of HMI in manufacturing.

Although the application of micro- and nanorobotics in manufacturing environments still seems rare, trends already show that nanomaterials or microelectronics will probably be part of numerous products in a few decades: the miniaturization of components of many everyday products, from sensors and smartphones to clothing or other textiles, will continue to

\footnotetext{
${ }^{1}$ In industrial manufacturing environments, stationary fences are needed for safety reasons to prevent physical contact by human with industrial robots in operational scenarios.
} 
progress. One important example is the electronics sector, where technical environments require detailed and accurate production processes and the use of micro robotic machines to assemble or produce ever smaller components. The number of industries that make use of micro- and nanorobotic systems however is slowly increasing, e.g., in the energy storage sector and the chemical sector [17]. With regard to the manufacturing life, the challenges and implications of human-centered manufacturing systems should be intensively observed with regard to (possible) increased blurring of boundaries of HMI. These might have a significant impact on the quality of work in manufacturing which seems still underestimated.

The first chapter of this article outlines the institutional relationship between technological innovation and work organization in manufacturing as discussed in recent decades. The second chapter approaches the analysis of technological developments with the extensive introduction of robotics and automation processes and the changes taking place in HMI in the manufacturing sector. In the third chapter, we briefly analyze robot applications in different sectors and related developments in work organizations. Here, we will focus on the application of emergent micro- and nanolevel robotics and discuss its impact on HMI. Our conclusions revisit and summarize the previous questions and outline further research needs.

\section{Robots and Organization of Work in Production Systems}

Early industrial robots, built back in the 1960s, emerged from the combination of two technologies: numerical control machine tools for precise manufacturing and teleoperators for remote handling of radioactive materials. In addition, the rapid development of integrated circuits, digital computers, and miniaturized components enabled the design and programming of computer-controlled robots by humans [18-23]. Whether the design and programming was done by engineers and technicians only, or also by machine operators, depended very much on the model of work organization.

The following decades were characterized by increasing automation in almost all sectors of the manufacturing industry [24]. Progress in automation became the technical and organizational basis for successful economic growth in many branches, such as the automotive and chemical industries. The introduction of robots into these production processes in the 1970s played a crucial role in the automation of work and the profound transformation of HMI. Since the late 1990s, robot applications have also been used outside of factories, mainly in sectors such as agriculture, services, and mobility. Here, huge potential of these applications has been identified. However, the introduction and application of robots in the health care sector has been (controversially) discussed [25-28].

Today, the use of robots in various fields is steadily increasing worldwide, which has triggered an intensive public and scientific debate about living and working "in the robot society" [29]. In these debates, robotics is portrayed as a technology that represents technological progress not only in production but also in its application in daily life [17, 30, 31]. Although empirical data show that innovations in robotics are basically related to applications in the manufacturing industry [32], robots seem to be the metaphor par excellence for describing the technical and social dimensions of future societies. At the same time, the concept of "robot societies" [31] raises doubts and concerns about human-robot interaction (HRI) and its impact on societal evolution. Public and scientific debates show that ethical reflection on HRI goes hand in hand with these concerns [27, 33, 34]. This seems especially true for NBIC technologies, which pose risks and hazards, in particular, in the field of organic material manipulation. De Jong and Borm conclude that "the scientific paradigm for the possible (adverse) reactivity of nanoparticles is lacking and we have little understanding of the basics of the interaction of nanoparticles with living cells, organs and organisms. A conceptual understanding of biological responses to nanomaterials is needed to develop and apply safe nanomaterials in drug delivery in the future" [35: 145]. The high degree of specialization in this field hampers the public and scientific debate.

As described above, robot applications have been successfully introduced in the manufacturing industry. Especially in recent decades, the technology density at workplace level has increased significantly through robotics [36]. Robot-based work environments, where one operator takes control of 
several machines and several work processes, have become much more complex. This technical complexity has led to significant changes, both at the workplace level and at the organizational level, which are being intensively discussed in many disciplines [37-41].

When introducing NBIC technologies, emphasis is usually placed on new forms of business models, new organizational patterns, and the use of technological platforms (networks) to support and promote competitive company strategies [42, 43]. However, socio-technological concepts addressing issues such as quality of work, HMI, or the formation of work teams to promote worker autonomy seem to be rather neglected, especially in the field of robotics [44, 45]. There appears to be a significant knowledge gap about the relationship between increasing automation, complexity of work contents, and changes in work quality [46-48]. This lack of knowledge becomes even more apparent with innovative applications of robotics on the micro- and nanoscale, e.g., in the manufacturing industry or in medicine $[49,50]$. To date, there are no studies analyzing the implications of robotics in terms of working conditions and forms of work organization of these sub-millimeter manufacturing systems. Technological innovations in this area are usually presented as "purely" technological development processes by engineering sciences that do not affect social and organizational conditions.

In the development toward the manufacturing of life, the informatization of production processes has played and still will play a central role from the very beginning [51]. Here, the introduction of robotics on micro and sub-millimeter scale will probably be accompanied by new standardization measures and order-oriented production. These issues of standardization are being integrated into the "rational" modes of production by NBIC technologies. It should be further explored whether working at the sub-mm scale entails (or not) is generating new modes of work in manufacturing. Thus, the deep analysis of HMI can make an important contribution to integrating cognitive, physical, and mental aspects of humans more strongly into work processes. Furthermore, this analysis may figure out whether manufacturing life is integrated into manufacturing processes.
The Shift from the Macro- to Micro- and to Nano level of HMI in Manufacturing Processes

As described above, robotic applications in manufacturing are usually embedded in complex sociotechnical organizational structures. However, experience shows that robotic applications do not necessarily replace operational tasks and thus human work [52, 53]. They enable changes in the division of labor between machines and working groups/workers which bring physical relief and thus help improve working conditions. Furthermore, they can contribute to increasing human competence and autonomy, especially in highly skilled jobs at shop floor level [54-56]. But can we conclude that these phenomena will also occur at the micro- and nanolevels of robotics? Will increasing competence requirements and autonomy shape HMI with this type of robots? There is still little empirical research on these questions.

The importance of socio-technical concepts for work environments in micro- and nanomanufacturing still seem to be underestimated. The impact of these technologies on new job profiles, new qualification requirements, or new task contents is still an open research field from the economic perspective [52-54]. On the other hand, research on new developments in robotics, especially in the engineering sciences, is strongly supported by public and private funding worldwide. The outcomes of that technical research can serve as tools for designing new work environments. In particular, technological developments in the fields of haptics, vision and control systems, and mobile capacity are leading to new forms of human-machine interaction (HMI) in the manufacturing industry. Social sciences could analyze the implications of those new technical concepts and contribute to the design of new work environments [57, 58].

At the microlevel, technical developments in the area of vision and control systems are becoming increasingly relevant in manufacturing processes. Haptics and mobile capacity, however, are less relevant for micro- and nanorobots than for industrial or service robots. Innovations in these fields mainly concern collaborative robotics, assistive bionics, exoskeletons, autonomous systems (ground, water, or air vehicles), and micro robotics. In these areas, the complexity of HMI at the working level is increasing significantly due to the use of various technologies, such as computerized numerical control (CNC) 
machine tools, automated guided vehicles (AGVs), and cyber-physical devices. For example, in many manufacturing companies, operators of flexible automation systems have to interact with CNC machine tools, collaborative robots, assistive mobile robots (AGVs or ground autonomous systems), and intermediate buffers with smart sensors.

Furthermore, the use of electronic processors and computer-controlled devices has increased significantly. This means that the technology density at these workplaces is much higher than at comparable workplaces in industry [36]. Due to the acceleration of processes, the complexity of tasks, and the required level of attention, HMI becomes much more intensive. The increasing complexity affects qualification requirements and work performance: the higher the complexity, the higher the competences required to perform the tasks. In companies that use NBIC technologies, this can lead to significant changes in the manufacturing workforce. Usually, a highly skilled worker, but without experience or special training, is not able to interact with this variety of devices. This is especially true in so-called "industry 4.0" environments, which require a higher level of skills and competences [56, 59].

Visions of production at the micro- and nanoscale are reflected in a prominent European report which focuses on aspects of working conditions, specifically the possibility of employee involvement [60]. The authors of the report assume that there are two dimensions of HMI and its integration in these new technical environments: (a) task discretion or the influence that employees can exercise on their immediate work tasks, (b) organizational participation or the influence that employees have on decisions in their work organization. Following these considerations, work in technically complex work environments (CWEs), such as micro- and nanomanufacturing, can enable a higher degree of operator control over their own task design and performance [37, 61, 62]. Problems that can arise in such work environments by quasiaccidents, failures, and other unexpected events. These can occur especially in the lower $\mathrm{mm}$ dimensions. The more complex the technical system is (equipment, communication system, accuracy requirements, systems architecture), the greater is the need to design the work environment appropriately (tasks, job allocation). At the same time, the greater the work autonomy and the qualification requirements, the clearer the work content and the decentralized decisionmaking processes must be. Experience shows that both dimensions, the social and the technical, must be designed together to prevent divergence in management strategies for the two dimensions and to integrate the technological complexity in the work environment. This seems to be especially true for the lower mm dimensions.

According to the US National Robotics Initiative's Roadmap for U.S. Robotics - From Internet to Robotics [63, 64] on nanomanufacturing, the classic complementary metal-oxide semiconductor (CMOS)based integrated circuits and computing paradigms are to be supplemented by new nanofabricated computing substrates. As stated in the report, advances in microelectromechanical systems (MEMS), lowpower very large-scale integration (VLSI), and nanotechnology already enable the use of sub-mm selfpowered robots (or nanorobots) in the healthcare, energy, and manufacturing sectors. New parallel, and even stochastic, assembly technologies for lowcost production are likely to emerge. Many conventional paradigms for manufacturing will, according to this technical vision [65], be replaced by new, yetto-be-imagined approaches to nanomanufacturing. Accordingly, the roadmap for nanomanufacturing and nanorobotics recommends basic research and development focusing on $[63,64]$ :

- 5 years: technologies for massively parallel assembly via self-assembly and harnessing biology to develop novel approaches for manufacturing with organic materials

- 10 years: manufacturing for the post-CMOS revolution enabling the next generation of molecular electronics and organic computers

- 15 years: nano-manufacturing for nano-robots for drug delivery, therapeutics, and diagnostics

The agenda of the US Roadmap is to regulate the development of nanorobots for medical applications until the early-2030s. Important steps toward achieving the goals are measures to promote technologies in the field of micro processing. In particular, a rapid development of technologies based on CMOS, VLSI, and MEMS is planned for the next years. The knowledge gained should be applied not only in industry but also in new systems for the medical (surgery robots) and healthcare sectors (assistive systems). 

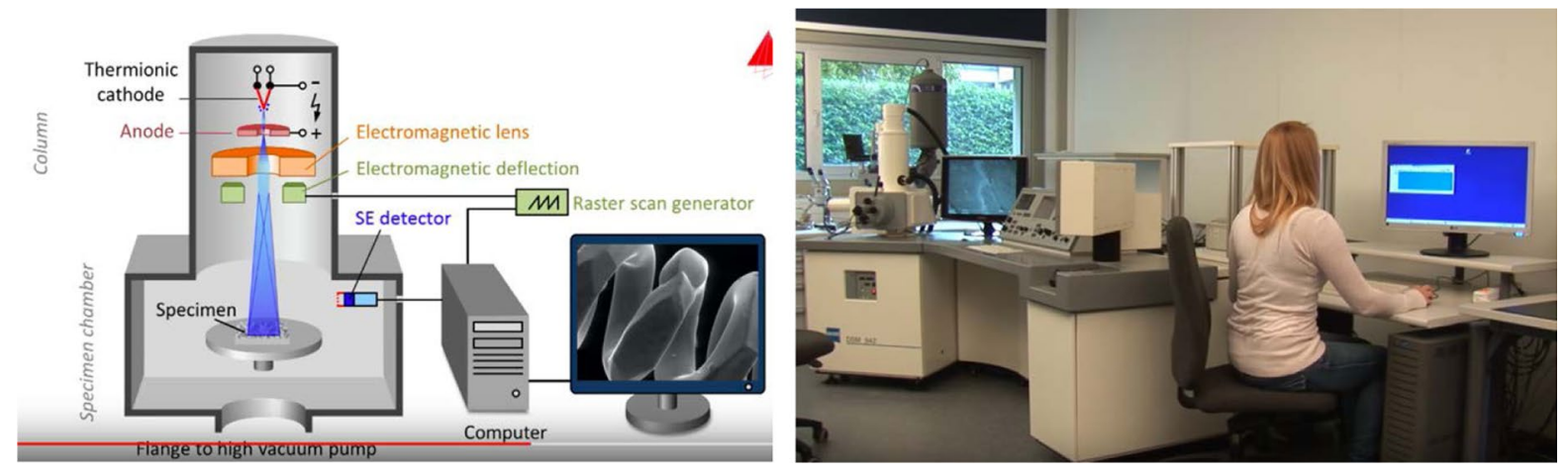

Fig. 1 Process and work environment with scanning probe microscope (SPM). SPM from Karlsruhe University of Applied Sciences (Germany)

According to Nelson et al., new industrial areas for micro robotics include assembly, inspection and maintenance, micro optics (positioning of micro optical chips, micro lenses, and prisms), and micro factories. Many of these applications require automated handling and assembly of small parts with sub-mm accuracy [8]. Some suppliers and manufacturers of micro optics need to configure automated micro electro-mechanical systems (MEMS) assembly machines for their devices. Other companies need to develop automated lens (for video camera production) and endoscope inspection systems (endoscopes at the point of use by medical professionals). Based on practical experience, this knowledge should also contribute to the development of new types of microelectronic products in the long run. Work structures in which such systems are used must differ from those where the components to be integrated or transformed can be visualized directly.

At nano level, the control in manufacturing process is also performed by highly specialized and precise machines, such as atomic force microscopes (AFMs) and scanning probe microscopes (SPMs), which do not allow the human operator to intervene directly. AFM is a very high-resolution type of SPM and produces images of surfaces using a physical probe that scans the specimen (organic or non-organic). In this way, the AFM provides a three-dimensional surface profile which allows the operator to work in ambient air or even in a liquid environment, as the following scheme and photo shows (Fig. 1). ${ }^{2}$

There is a significant shift in the work environment, which is due to the dimensional features of the nanoscale components: materials at this level behave differently than on a conventional scale. There is a higher chemical reactivity, while the object's surface area in relation to its volume is very small. At the microlevel, the volume of components cannot be monitored directly by operators, but through information with computerized parameters. However, at the nanoscale, special devices are needed to intervene in the process, which means the operator visualizes and works through microscope the manufacturing process. The point is that at both dimensional levels micro and nano - HMI takes place through indirect information about the production status, and augmented reality devices may be used to control the processes. At microlevel, the worker uses imaging sensors to access information on the process control, but at nano level, the use of special microscopes is required to collect information that will be provided through augmented reality (as shown in the above scheme of Fig. 1).

\footnotetext{
${ }^{2}$ All images from Figs. 1 and 3 are from a video (https:// www.youtube.com/watch? $\mathrm{v}=\mathrm{GY} 91 \mathrm{fO}-\mathrm{tVfE}$ ) produced in the lab of Prof. Dr.-Ing. Rainer Schwab, Hochschule Karlsruhe (Karlsruhe University of Applied Sciences), Germany.
} 
Fig. 2 Operation with atomic force microscopy (From https://www. youtube.com/watch? $\mathrm{v}=$ GybH5DfWG9w (Park Atomic Force Microscopy))
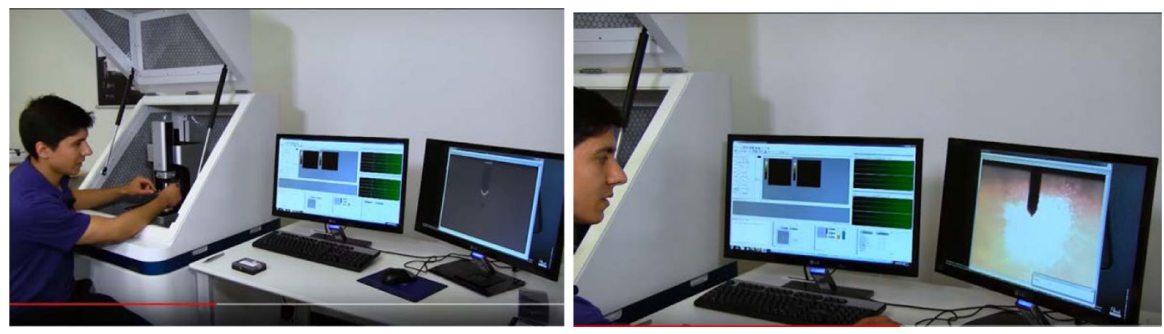

The use of 3D images becomes important and standard in micro- and nano production with robots, in particular in electronics or precision metal engineering. According to De Santis et al., the "dependability of complex robot systems in anthropic domains during normal operations is threatened by different kinds of potential failures or un-modelled aspects of sensors, control/actuation systems, and software architecture, which may result in undesirable behaviours" [66]. Some of the undesirable events in work environments with NBIC technologies, sensors, control systems, software, and manipulation at sub-mm levels can have safety implications. In the context of medical robotics, Fei et al. stress that "safety is not only an engineering issue but also a management project" [25]. The same assumption can be applied to any other type of robot used in manufacturing, as for EN ISO 10218:2011 [67-69] standards about safety requirements for industrial robots. However, while HMI analyses usually consider various aspects, such as autonomy, level of shared interaction, handling of sensors and sensor fusion, task content, and ratio between robots and workers, safety conditions in nonphysical interaction are rarely considered.

As described above, system integration is one of the major challenges for robotics in CWE in manufacturing. Micro- and nanorobots will be used in the near future and will constitute a limiting factor in the integration of production cycles. Because "nanoobjects do not exist without technological mediation: they require the use of SPM or AFM connected to powerful computers and software. In this respect they instantiate Bachelard's notion of 'phenomenotechnics': they are constructed by technological means and require a convergence of research efforts and a multidisciplinary community. Nanoscale objects only came into being via a technological macrosystem, a network of information technologies" [70]. As Bensaúde-Vincent points out, these types of technologies will play a central role in the redesign of work practices. Nanotechnology in particular will establish a new quality of HMI, which is characterized by the complexity, the degree of abstraction of the content, and the relationship of the technical intermediary to its "working object." This means that image mediation will become the standard in work environments that offer a new quality of HMI: simulation-based interaction, where the object to be assembled or manufactured only becomes visible through novel microscopes.

The following pictures show the work with an AFM in a manufacturing environment (Fig. 2).

As shown in the pictures above, several devices are connected to the workplace interacting with the AFM, and "each AFM instrument should be miniaturized as much as possible to maximize the number of instruments that can be operated in parallel", as referred by Sadeghian et al. [69] about these machines (atomic microscopes).

The SPM, a special type of AFM, has the disadvantage of producing images in black and white or greyscale, which can lead to distortion of the shape or size of a specimen or sub-mm object. Computers are used to compensate for these distortions and generate real-time color images that provide the operators with real-time information, e.g., on interactions within cellular structures, harmonic responses, and magnetic energy (see pictures below in Figs. 3 and 4).

With a scanning tunneling microscope ${ }^{3}$ (see pictures above), the human operator installs the cantilever with the specimen to be manufactured or assembled and then controls the process via a computer terminal that receives data from several sensors. The

\footnotetext{
3 https://en.wikipedia.org/wiki/Scanning_tunneling_microscope
} 

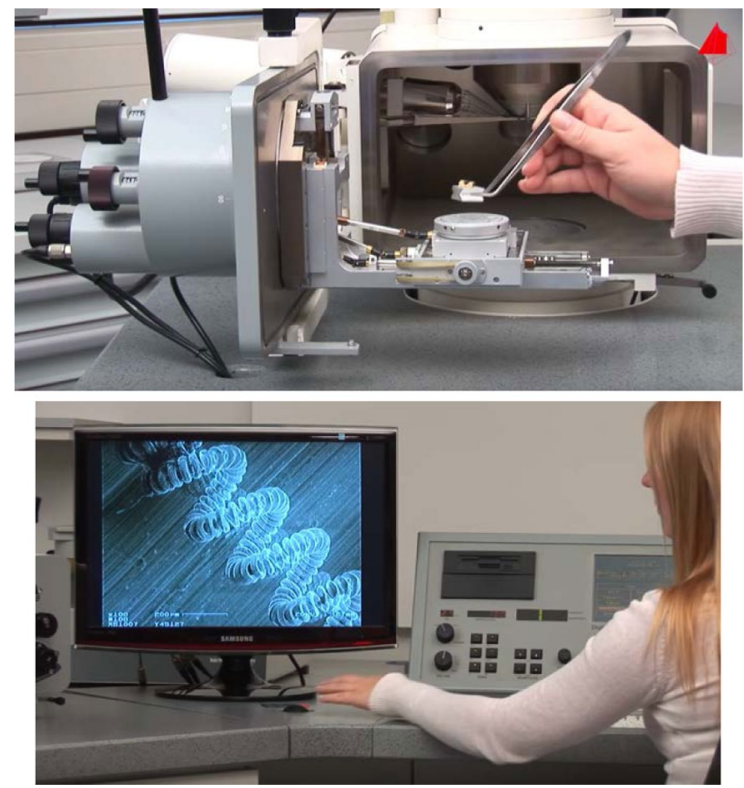

Fig. 3 Operation of an SPM (https://www.youtube.com/watch? $\mathrm{v}=\mathrm{GY} 91 \mathrm{fO}-\mathrm{tVfE}$ )

feeding of the specimen chamber can also be automated when connected to an industrial robot (not shown in the above photo). The following image shows how an STM manipulates atoms to assemble a new object or even a nanorobot.

Khare et al. explain in their article on sub-mm additive manufacturing: "SPM methods allow direct-write patterning and in situ imaging by contact or near-contact interactions of a substrate with a nanoscale probe, typically at the end of an atomic

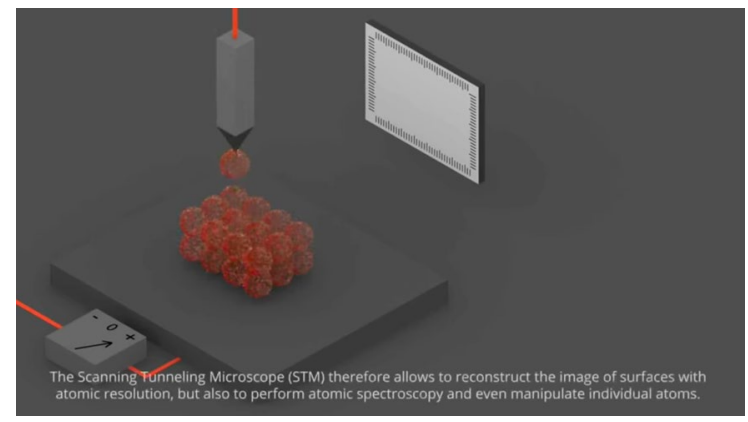

Fig. 4 Example of manufacturing process using a STM (Physics Reimagined group (LPS, CNRS Universite Paris-Sud) with funding of Labex PAL. https://www.youtube.com/watch?v= HE2yE8SvHmA) force microscope (AFM) cantilever" [71]. Therefore, this method, as seen in Fig. 4 from the Laboratory of Solid-State Physics (LPS) form the CNRS and University of Paris-Saclay, can be applied to low batch production industry or for prototyping (medical products or electronics).

At these scales, simulation, anticipation, and production instances are defined by machines, while at the same time the technical competences of humans to work with such objects must increase. Such competences are related to the task contents, such as nano handling and manipulation needs, and the scope of the overall processes. Here, it seems that the boundaries of HMI with respect to machine autonomy processes may become blurred. The high complexity of the technological systems in which humans are involved probably leads to a loss of control rather than an increase in autonomy. In other words, since the complexity of the systems requires higher skill levels to interpret the computed visual information, these machines can lead to a higher degree of automation of the manufacturing processes (additive or not) on an industrial level. It can be assumed that, under these circumstances, the human operator will lose control of the work process, while keeping his or her autonomy. This autonomy can be at the decision level or at the process level. The operator can be entitled to such autonomy because of the competences required to perform the necessary tasks.

There are several authors that demonstrate different application experiences with these levels of micro- and nanomanufacturing possibilities. For instance, Bogue states on micro- and nanorobotics: "As yet, the technology is in its infancy, but a growing number of academic groups are studying nanorobotic concepts" [72]. Fabrication by deposition, etching, and lithography (additive manufacturing), reliable electronic interconnect processes, energy storage and conversion (e.g., batteries, fuel cells), and production of photovoltaic nanomaterials are recent examples of industrial applications. The range of products focuses on applications that will play a major role in the near future. However, according to Khare et al., "methods such as electron-beam lithography and focusedion beam printing work in a serial writing mode are expensive. In addition, these top-down nanomanufacturing methods are intrinsically planar, requiring multiple postprocessing steps which limit patterning flexibility and result in a large excess of material 
Fig. 5 Work operation examples with an SEM. a Pomona College Physics and Astronomy Department (USA) (Source: https:// www.pomona.edu/academics/ departments/physicsand-astronomy/facilities/ scanning-electronmicroscope). b Laboratory Testing Inc. (USA). (Source: https://www.labtesting.com/ services/materials-testing/ metallurgical-testing/semanalysis/). c Zeiss Auriga SEM-FIB Workstation installed at CENIMATli3N (Portugal)

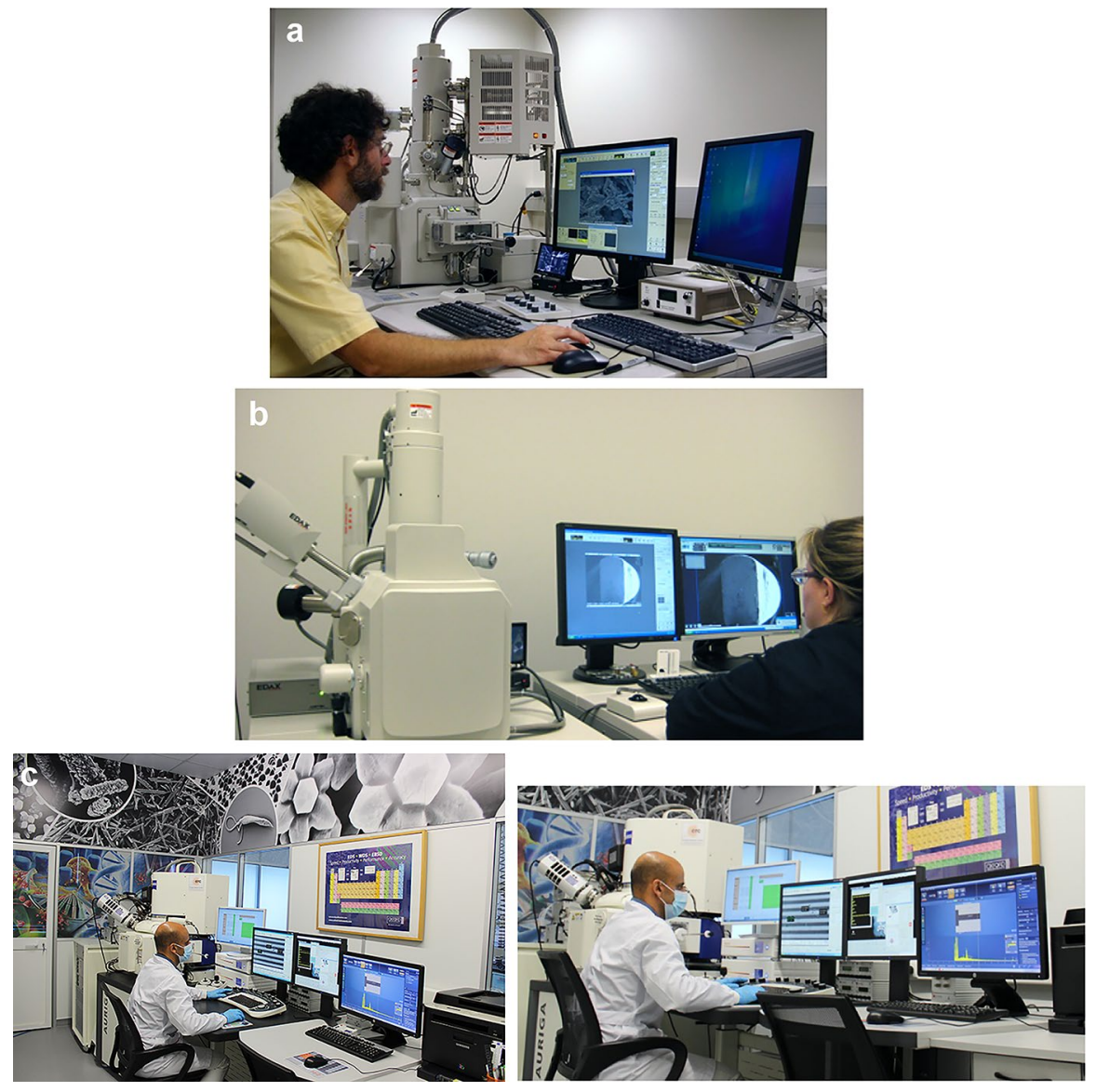

waste during manufacturing. Additive nanomanufacturing provides design flexibility and allows direct write patterning of metallic, ceramic and insulating nanostructures, which are typically precluded with photolithography" [71]. This lithography method uses both micro- and nanomanufacturing approaches in additive processes. HMI in such systems is similar to that of special microscopes used in sub-mm manufacturing.

$\mathrm{Ru}$ et al. demonstrated automated nanomanipulation inside a scanning electron microscope (SEM) for a well-structured nanomanipulation task via visual servo control. Here, four-point probe measurement of individual nanowires was achieved automatically by controlling four nanomanipulators with SEM visual feedback [73]. In contrast, Yang et al. point out the challenges of coordinating such complex nanomanipulation processes: "high efficiency nanomanipulation requires multiple degrees of freedom, including rotation, for orientation control of nanotubes and automated nano-handling control. Besides, a single nanomanipulator itself has limited capabilities, but the coordinated effort of a multitude will produce the desired systemlevel results. Coordination is needed across the board - for communication, sensing, and acting - which poses a major research challenge. The scale and dynamics of nanorobotics systems precludes centralized coordination and global sharing of states" [74]. The following pictures show examples of human interaction with SEMs (Fig. 5).

The pictures above show laboratories that operate and test SEM systems. In most cases, they also provide services for companies (prototyping, testing, quality control). The examples vary from Germany to USA and to Portugal. The working processes in those labs are very similar and are being applied elsewhere as we understood from the interviews made. However, 
there are also companies that provide such component manufacturing services, and some larger industrial companies are equipped with their own SEM systems. The cases at service and industry sectors are not so frequent. However, it is clear that the number of cases will increase quickly in the next years in a correlated fashion as product and component miniaturization is also growing in different sectors. The economy sectors that potentially will increase the use of miniaturized products and components can vary from electronics and optics, to automotive, to pharmaceutics, or even to medical devices. Many others will follow.

Overall, the field of sub-mm robotics covers the manipulation of objects at the micro- and nanoscale (manipulators) as well as the design and fabrication of autonomous robotic agents, as referred by Nelson et al. [8] and Requicha [75]. The procedures required for molecule manipulation or the development of artifacts that can intervene in organic structures are likely to transform production processes and HMI in these work environments. Changes in HMI result from the separation between the operator and the object of transformation. Usually, the operator controls the process via computer terminals (see pictures above). The object of transformation is located in the specimen chamber, which is closed by means of a high-vacuum pump. At the micro- and nano levels, sensors and data processing play a central role in the work performance as soon as direct manipulation is no longer possible. Work tasks are mediated through ICT, and the work contents must follow standardized procedures. At the sub-mm scale, humans have to interact with specialized machines with a high degree of ICT integration on an extremely abstract level. They work in a much more complex work environment, with different types of machines and a variety of devices.

Looking at the empirical experience with NBIC technologies in industry, it is striking that knowledge about the interrelation between micro- and nanorobotics and the design of task organization for machine operation seems to be proportional to the dimensional level: there is very little knowledge on the socioorganizational implications of microrobots and almost no knowledge at the nanorobotics level. Therefore, a closer look at the shift from the macro- to micro- to nano level in future systems of manufacturing seems worthwhile.

\section{Human-Machine Interfaces at the Micro- and Nano levels}

Whereas socio-technical concepts in manufacturing have been evaluated with regard to (economic) efficiency as well as with regard to working conditions, empirical information about the impact of manufacturing on a sub-mm scale is still missing. In scientific debates, another aspect focuses also on the new quality of human-machine interface, where robotics becomes a mediated function between the operator and the product or component to be assembled or manufactured. These changes are based on the structure of manufacturing applications which should be developed in the long run on a specific socio-technical concept in this field.

The technical precision increases when the manufacturing process is driven into the microlevel, and even clearer, into the nano level. The management becomes also more central in the field of emerging technologies applied in these last dimensions. Here, it seems important to analyze in depth which normative perspective is leading robotic applications. Whereas in production sector the socio-technical concept of robotics has led to processes of increased codification, commodification, standardization, and fragmentation, according to Schmiede [51], similar developments at micro- and nano levels are still under observation.

As well for the nano assembly, it is necessary to use SPM. Although microscopes are normally used for imaging, it was recognized soon after their invention that they can also modify the samples, as Requicha et al. point out in their paper [75]. AFM can be used for nano assemblies, but only in ambient conditions. Thus, the standard use of the AFM is as an imaging instrument. This research team concludes that AFMs provide effective means for fabricating nanodevices and nano system prototypes and products in small quantities [75].

Another element that will have implication on the modes of HMI with micro- and nanomachinery is that complex communication and information management is controlling the functioning of the system. The decision process has several levels of determination, and unexpected events can have higher risk effects for the process performance and task completion. Studies from Dalgaard [23] or Bernstein, Crowley, and Nourbakhsh [76] already indicate this. 
In conventional industrial manufacturing, the robot operators (from the traditional industrial robots to the most advanced collaborative robots) are using their individual senses like their vision, their senses of touching, their senses of smelling and hearing to understand and interact with the work environment. In manufacturing, an increase of integration of service robotic technology is widely expected and through the deployment of robots into novel areas of manufacturing, as Hirsch-Kreinsen and Karacic [9] or Moldaschl [77] already concluded.

However, new problems are occurring with the manufacturing at nanoscale. It needs unusual equipment (like the above-mentioned SPM and AFM) and it can be applied for small quantities of products. Besides this, the operator should be at distance from the manufacturing objects. There are existing two basic principles for the fabrication of microand nanorobot devices: the bottom-up and top-down approach. Assembling smaller components to the final product is called bottom-up approach, whereas reducing a big to a small piece is called top-down approach. Since fabrication methods determine the design of a robot, the required robot performance in a specific application field is indirectly linked to these fabrication methods. Micro- and nanofabrication methods are of major relevance for successful implementing micro- and nanorobots $[22,78]$. Thus, microrobots with the application of in-pipe inspections, operation in microenvironment and microsurgery of blood vessels will be very useful to industrial and medical fields, as Guo et al. conclude [26].

Some robot manufacturers are developing new cell production assembly system, in which physical and information supports are provided to the human operators, reinforcing the safe cooperation with the robot while providing instructions on the operations to be performed [79-81].

Interestingly, the European Multi-Annual Roadmap describes "in the context of manufacturing, the greatest potential is for functions which contribute to a reduction of programming and configuration requirements in deployed systems. There are formulated clear benefits for small lot size systems in reducing the time and skill needed to reconfigure an adapt systems to new processes" [82]. Examples, hereby, can be used from "man-robot interaction with open-end learning process, robot apprentice learning from experience, from various workers, abstraction, etc." that will be found in several case studies. The ability levels for human interaction that are relevant will be from the level 5 (Social interaction), but a special focus will be found for levels 6 (Complex social interaction) and 7 (Intuitive Interaction). From a technical side these descriptions seem already comprehensible, from a social and organizational side, however, these descriptions seem open in its applications. For the purpose of understanding the HMI levels, it seems important to include the human dimension.

This means that the new forms of interaction with micro- and nano level machinery will need much higher Technology Readiness Levels (TRL). As known, TRL is a type of measurement system used to assess the maturity level of a particular technology, developed by NASA. ${ }^{4}$ Later it was adapted and adopted by the European Commission (EC) from 2014 at the Framework Programme Horizon 2020. Whenever the TRL, the more critical becomes the technology readiness, the more important is the definition of the limits and capacities of the human agent.

In the Multi-Annual Roadmap on Robotics, established by the EC for the above-mentioned Framework Programme of Research and Development, the "Human-Robot Interaction Levels" under chapter "Interaction Ability" is described in detail. It applies to all types of robots, and not specifically to nanorobotics. There [83] "the following set of levels relate to the interaction between users and the robot system. This set of ability levels are distinct from the cognitive human-robot interaction levels as they define the method of interaction independently of the

\footnotetext{
$\overline{4}$ https://www.nasa.gov/directorates/heo/scan/engineering/ technology/txt_accordion $1 . h t m l$
} 
cognitive context". The level $0,{ }^{5} 1,{ }^{6} 2,{ }^{7}$ and $3^{8}$ reveal the basic levels of interaction ability in the HMI, and they are mostly applicable to most applications of industrial robots. The next levels (TRL 4 to 6 ) can be more suitable to micro- and nano-manufacturing.

- Level 4-This kind of interaction is mostly common to industry companies that use welding or gluing robots, with no sequential operations. These applications can be as well used for nano levels. There the system can operate autonomously during some parts of a task or in some tasks. This can be also the case for some operations with micro-assembly. Once this task or sub-task is complete the human operator will either select the subsequent task or intervene to control the system by direct interaction to carry out a task, as in the application examples mentioned. This results in alternating sequences of autonomous and direct control of the system by the robot operator.

- Level 5-The interaction level of task sequence control is not so common, as the robot system should be able to execute sub-tasks autonomously which involve a higher level of decisional autonomy than the pre-defined tasks in Level 3. The human operator is required to select the next subtask resulting in a sequence of actions that make up a completed task, even for micro- and nano robots.

\footnotetext{
${ }^{5}$ When it is possible that some robots will effectively have no operational interaction with a user.

${ }^{6}$ When the system can translate, alter, or block controls within parameters set by the user or system. The operator controls are in the form of parameters that alter the control of the robot. These parameters may be continuous quantities, for example a steering direction, or binary controls. In most traditional standalone industrial robots, the control executed by operators has usually this level of interaction.

7 The operator controls the robot by physically interacting directly with it. The robot reacts to the user interaction by feeding back physical information to the user via the contact point. For example, the user "teaches" a motion sequence to the robot or feels the surface of an object the robot is in contact with. This interaction is possible in more advanced robots with safety features that allow or enable the direct interaction between the operator/user and the machine/robot.

8 The system is able to execute pre-defined actions autonomously through programming, and the human operator selects the subsequent action at the completion of each action.
}

- Level 6-The system is able to recognize when it is unable to proceed or when it requires user input to select alternative strategies or courses of action. These alternatives may involve periods of direct control. This is the case when robots are integrated in more complex systems with interaction with other machines or robots. As usually there are no applications in micro- or nanomanufacturing requiring this level of operation, the examples of this level of interaction are not applied, or at least there are also no literature references of any example, although conceptually they may be possible.

For the Level 7 (Task selection) and Level 8 (Mission Goal setting), we also do not have any reference for micro- and nanorobotics, as verified by the literature review, as well by the expert interviews. Even for "conventional" industry robotics, the cases are less common. These levels of interaction imply that the robotic systems are able to autonomously execute tasks but requires the human operator to select between strategic task alternatives in order to execute a mission (TRL7), or the system will be able to execute tasks to achieve a mission where the human is able to interact with the system to direct the overall objectives of the mission. The levels of autonomy are dependent on technology development, but mostly dependent on social determinants: the operator skills and competences, and the work organization models [84]. In this roadmap, the "Human-robot interaction feedback" is defined as an "ability to command a robot depends on the user's perception of the state of the robot" [83]. Here are also different levels of robot feedback. It starts on level 0 where there is no feedback, ${ }^{9}$ and continues on $1 .{ }^{10}$ The following levels are applied to micro- and nanorobotics:

- Level 2 - Robots operating with micro components in the electronics sector provide vision data

\footnotetext{
9 The traditional industrial robots that were introduced from the last mid-century in the manufacturing system produced no feedback to the operator. He/she could even not follow visually the performance of the programed machine, because it would be located among other machines, with no interaction with humans.

${ }^{10}$ Visual feedback through direct observation. The simple robot system does not provide any means of feeding back information to the operator.
} 
feedback. The human operator must interpret this visual imagery to assess the state of the robot or its environment.

- Level 3 - A simple haptic feedback is delivered to the user via a single point of contact, for example a joystick. Some industrial cases of robots applied to additive manufacturing methods with micro process using robots to handle specimen chambers at SPM provide this level of feedback.

- Level 4-More recent system of robots operating with micromanufacturing or even microrobots are able to feedback to the operator signals and forces that augment the force information (augmented haptic feedback). The augmentation enhances the interaction between the user and the robot. In the future, it is also to be applied to nanorobots in the electronics sector.

These feedback levels nicely show the (new) quality of HMI in these complex systems like the image interpretation and new types of haptic feedback. The next levels ${ }^{11}$ are presently objectives for more advanced robotics in some manufacturing industries, but not at micro- or sub-mm levels. The last feedback level (TRL 8), for example, would require that the robotic system is able to augment the experience of tele-presence with additional information that enhances the interaction between the user and the robot. Some changes can be expected at the level of communication between these dimensional robots and other robots or humans. Presently, just level 4 feedback is known in few cases, as was reported to us in interviews with field experts.

The boundaries of HMI at micro- and nano levels imply enhanced interaction augmentation, with additional information, with additional sensing or additional interpretation. It seems that these effects may provide new modes of HMI in manufacturing with robots at micro and nano scale. However, standardization and linearity of processes and order-oriented production will be established also at micro and nano scale $[66,74,76,85]$. With regard to the enhanced interaction augmentation in the HMI, Adam Greenfield points out that these new systems "confronts us

${ }^{11}$ Level 5 -Multiple point feedback; 6 - Augmented multiple point feedback; 7 - Tele-presence; and 8 - Augmented telepresence. with an interlocking series of concerns, ranging from the immediately practical to the existential. The initial reservations center on the technical difficulties that are involved in articulating an acceptably high-quality experience" [86].

\section{Boundaries Between Manufacturing Life and Work - Conclusions}

The Intel co-founder, Gordon Moore, mentioned that the number of transistors incorporated in a chip will approximately double every 24 months. As a result, the transistor scale gets smaller and smaller according to the famous Moore's Law. However, the global semiconductor silicon wafer market is expected to reach US $\$ 13.64$ billion by 2025 (being 9.85 billion in 2019). Semiconductors have emerged as the building blocks of all modern technologies, and wafers remain the core component of many microelectronic devices and the cornerstone of the electronics industry. The engineering behind an integrated circuit goes far beyond the simple assembly of individual components. In fact, microscopic circuit patterns are built on multiple layers of different materials. These steps are repeated several hundred times until the chip is finally finished. ${ }^{12}$ The above descriptions impressively demonstrate the market dimension of products manufactured with robotics at the sub-mm scale. However, due to the high level of technical specialization, the public has little knowledge about the manufacturing processes of products such as smartphones, tablets, and other digital devices.

Given the ongoing innovation process of microand nanoscale robotics in manufacturing, the overarching question is how deep and how complex the impact on HMI is. What are the side effects of new technical features, especially if they are developed at the micro- and nano levels? How does HMI change at this scale? Will the boundaries in HMI change? How will this affect the quality and organization of work?

The article confirms the hypothesis that working with robotics at the sub-mm scale will probably blur the boundaries of HMI in manufacturing and bring new challenges. Although there is little empirical evidence, it seems that HMI will become more involved

\footnotetext{
${ }^{12}$ Samsung webpage http://news.samsung.com/global
} 
in the physical interface, but the boundaries of HMI will become blurred by more intense interaction via information collection and control.

As described above, the shift from macroscale robotics (industrial and collaborative robots) to micro- and nanoscale robotics is characterized by an increase in the technical complexity of HMI at the shop floor level. This is similar to experiences in the manufacturing industry with new forms of interaction between operators and CNC machine tools or collaborative robots. The interaction with machines at the sub-mm scale and the large number of electronic processors, vision systems, and computerized devices used in these new processes place new demands on operators, while at the same time, the possibilities for human manipulation of the work processes are decreasing. Control is achieved through automotive procedures and feedback, which increases the autonomy of the manufacturing process. Due to the increasing autonomy of the processes, the boundaries of HMI become blurred. Interestingly, this has not been the case with automotive production in the process industry, as Kidd [46] and Brödner [62] have already demonstrated. But will the broadened parameters of the "Industry 4.0" concept with the dissemination of cyber-physical systems and industrial IoT robots (macroscale) bring similar developments? Previous works from Pfeiffer [59] or from us [87] has focused on that and the answer probably is, yes. It seems that HMI at the sub-mm scale is characterized by a new quality of interaction with more complex devices in the interaction process, but less work autonomy of humans. As the article showed, working at the micro- and nanoscale is technically and organizationally complex. The assumptions about the impact of HMI in these areas are preliminary, and further research is needed, which will be outlined in the following steps:

In a first step, problems, limits, and potentials of micro- and nanoscale robotics should be identified and analyzed for different models of organization in complex work environments. In addition, the side effects of technical applications should be explored comprehensively in terms of both HMI and organizational structures, also taking into account the human dimension in terms of "improved" working conditions, as Bethel and Murphy [88] already demonstrated some years ago.

In a second step, further research should identify - mainly based on scenarios - new developments where technical achievements (3D operation, augmented reality, haptics, micro- and nanomanipulation) can be applied in more sectors of the manufacturing industry $[74,89,90]$. The new dimensions of micro- and nanorobotics in several sectors (metal industry, microelectronics, textiles, medical devices) give rise to new forms of HMI. The strong development toward miniaturization of electronic devices and components in manufacturing is accompanied by an increasing need for simulation tools for the assembly of sub-mm components and control of the novel robots $[8,78,91]$. Without doubt, in the long run, interaction will be mediated through computer imaging and will take new directions, where direct process control by humans is probably no longer possible.

As mentioned in the beginning of this article, at both dimensional levels - micro and nano - HMI takes place through indirect information about the production status, and augmented reality devices may be used to control the processes. That being said, we can conclude that working on these scales requires, on the one hand, increased abstraction and simulation skills of the workers. On the other hand, the application of this type of technical tools and artifacts is associated with increased standardization of work processes. These changes in HMI and thus at workplace level require critical analysis of their impact in terms of safety standards, new forms of control, and workers' autonomy in work environments at the micro- and nanoscale.

Acknowledgements The authors would like to thank for the collaboration of interviewers from CENIMAT and CTS research centers at UNINOVA (Portugal) and the sabbatical scholarship provided by the Portuguese Foundation for Sciences and Technology (SFRH/BSAB/135113/2017) Special thanks are also given to Ms. Sylke Wintzer, from Karlsruhe Institute of Technology, for the language revision. Finally, we also would like to thank for the contribution made by the two anonymous reviewers that provided the chance to significantly improve the article.

Funding Open Access funding enabled and organized by Projekt DEAL. CICS.NOVA research support through national funds of FCT-Foundation for Science and Technology, I.P., within the scope of the project UIDB/04647/2020.

Open Access This article is licensed under a Creative Commons Attribution 4.0 International License, which permits use, sharing, adaptation, distribution and reproduction in any medium or format, as long as you give appropriate credit to the original author(s) and the source, provide a link to the Creative Commons licence, and indicate if changes were made. The images or other third party material in this article are included in the article's Creative Commons licence, unless indicated 
otherwise in a credit line to the material. If material is not included in the article's Creative Commons licence and your intended use is not permitted by statutory regulation or exceeds the permitted use, you will need to obtain permission directly from the copyright holder. To view a copy of this licence, visit http://creativecommons.org/licenses/by/4.0/.

\section{References}

1. Blumenberg $\mathrm{H}$ (1985) The legitimacy of the modern age (trans. Wallace RM). MIT Press, Cambridge, MA

2. Latour B (1993) Aramis ou l'amour des techniques. Edition la découverte, Paris

3. Krings B-J, Rodríguez H, Schleisiek A (eds) (2016) Scientific knowledge and the transgression of boundaries. Springer VS, Wiesbaden

4. Allenby B, Sarewitz D (2011) The techno-human condition. MIT Press, Cambridge, MA

5. Compagna D, Kohlbacher F (2015) The limits of participatory technology development: The case of service robots in care facilities for older people. Technol Forecast Soc Chang 93:19-31

6. Malsch T, Schulz-Schaeffer I (2007) Special Section on Socionics. J Artif Soc Soc Simul 10(1)

7. Funken C, Schulz-Schaeffer I (eds) (2008) Digitalisierung der Arbeitswelt. Zur Neuordnung formaler und informeller Prozesse in Unternehmen. VS Verlag, Wiesbaden

8. Nelson BJ, Dong L, Arai F (2008) Micro/nanorobots. In: Siciliano B, Khatib O (eds) Springer handbook of robotics. Springer, Berlin, pp 411-450

9. Hirsch-Kreinsen H, Karacic A (eds) (2019) Autonome Systeme und Arbeit. Perspektiven, Herausforderungen und Grenzen der Künstlichen Intelligenz in der Arbeitswelt. transcript, Bielefeld

10. Prewett MS et al (2010) Managing workload in humanrobot interaction: A review of empirical studies. Comput Hum Behav 26:840-856

11. Wallhoff $F$ et al (2010) A skill-based approach towards hybrid assembly. Adv Eng Inform 24:329-339

12. Moniz $A B$ (2015) Intuitive interaction between humans and robots in work functions at industrial environments: The role of social robotics. In: Vincent J, Taipale S, Sapio B, Lugano G, Fortunati L (eds) Social Robots from a Human Perspective. Springer, Heidelberg, pp 67-76

13. Will-Zocholl M (2017) Virtual Temptations. In: Briken K, Chillas S, Krzywdzinski M, Marks A (eds) The new digital workplace. How new technologies revolutionise work. Palgrave MacMillan, London, pp 62-87

14. Taylor FW (1911) The principles of scientific management. Harper \& Brothers, New York

15. Friedmann G (1946) Problèmes humains du machinisme industriel. Gallimard, Paris

16. Kern H, Schumann M (1970) Industriearbeit und Arbeiterbewusstsein. Europäische Verlagsanstalt, Frankfurt am Main

17. Šabanović S (2010) Robots in society, society in robots. Int J Soc Robot 2:439-450

18. Ebel K-H (1987) The impact of industrial robots on the world of work. Robotics 3:65-72
19. Skordas Th, Robrock KH (1997) An overview of Robotics Technologies in RTD Programmes of the European Community under FP4. European Commision, Brussels

20. Moniz AB (2007) The collaborative work concept and the information systems support perspectives for and from manufacturing industry. Technikfolgenabschätzung - Theorie und Praxis 16(2):49-57

21. Hägele M, Schaaf W, Helms E (2002) Robot assistants at manual workplaces: Effective co-operation and safety aspects. In: Proceedings of the 33rd ISR (International Symposium on Robotics). IFR, Stockholm

22. Siciliano B, Khatib O (eds) (2008) Springer handbook of robotics. Springer, Berlin

23. Dalgaard L (2011) Rational system-level design methodology for autonomous robotic systems. PhD thesis, Danish Technological Institute, Centre for Robot Technology and University of Southern Denmark, Maersk Institute

24. Brödner P (1990) Technocentric-anthropocentric approaches: Towards skill-based manufacturing. In: Warner M, Wobbe W, Brödner P (eds) New technology and manufacturing management. John Wiley \& Sons, Chichester

25. Fei B et al (2001) The safety issues of medical robotics. Reliab Eng Syst Saf 73:183-192

26. Guo S, Pan Q, Khamesee MB (2007) Development of a novel type of microrobot for biomedical application. Microsyst Technol 14(3):307-314

27. Compagna D, Weidemann A, Marquardt M, Graf P (2016) Sociological and biological insights on how to prevent the reduction in cognitive activity that stems from robots assuming workloads in human-robot cooperation. Societies 6:29. https://doi.org/10.3390/soc6040029

28. Krings B-J, Weinberger N (2018) Assistant without master? Some conceptual implications of assistive robotics in health care. Technologies 6(1). https://doi.org/10.3390/ technologies6010013

29. van Est R, Kool L (eds) (2014) Working on the robot society. Visions and insights from science concerning the relationship between technology and employment. Rathenau Instituut, Den Haag

30. Duysburgh P, Elprama SA, Jacobs A (2014) Exploring the social-technological gap in telesurgery: Collaboration within distributed or teams. In: Proceedings of the 17th ACM conference on computer supported cooperative work \& social computing. pp 1537-1548

31. Royakkers L, van Est R (2016) Just ordinary robots automation from love to war. Taylor \& Francis Group, London

32. Moniz AB (2012) Anthropocentric-based robotic and autonomous systems: Assessment for new organisational options. In: Decker M, Gutmann M (eds) Robo- und informationethics: Some fundamentals. LIT, Zürich, pp 123-157

33. Nagenborg $\mathrm{M}$ et al (2008) Ethical regulations on robotics in Europe. AI Soc 22(3):349-366

34. Nida-Rümelin J, Weidenfeld N (2018) Digitaler Humanismus. Eine Ethik für das Zeitalter der Künstlichen Intelligenz. Piper, München

35. De Jong W, Borm P (2008) Drug delivery and nanoparticles: Applications and hazards. Int $\mathbf{J}$ Nanomed 3(2):133-149 
36. Curkovic P, Jerbic B, Stipancic T (2013) Coordination of robots with overlapping workspaces based on motion coevolution. International Journal of Simulation Modelling 12(1):27-38

37. Emery F, Trist EL (1960) Socio-technical systems. In: Churchman CW, Verhulst M (eds) Management science. Models and techniques, vol 2. Pergamon, London

38. Anderson RL, Gartner WB (1985) When robots and people work together. Robotics 1:69-76

39. Hirsch-Kreinsen H (1993) Use of CNC and alternative methods of work organisation. Comput Integr Manuf Syst $6(1): 3-8$

40. Grugulois IV (2005) Changing boundaries, shaping skills: The fragmental organizational form and employee skills. In: Marchington $\mathrm{M}$ et al (eds) Fragmentation work, blurring organizational boundaries and disordering hierarchies. Oxford University Press, Oxford, pp 199-216

41. Frei R, Barata J (2010) Distributed systems - from natural to engineered: Three phases of inspiration by nature. International Journal of Bio-Inspired Computation 2(3/4):258-270

42. Huws U (ed) (2006) The transformation of work in a global knowledge economy: Towards a conceptional framework. HIVA-K. U. Leuven, Leuven

43. Huws U, Spencer N, Syrdal DS, Holts K (2017) Work in the European gig economy: Research results from the UK, Sweden, Germany, Austria, The Netherlands, Switzerland and Italy. Foundation for European Progressive Studies, Brussels

44. Devlin K, Rosenberg D (2008) Information and human interaction. In: Adriaans P, van Benthem J (eds) Handbook of the Philosophy of Science, vol 8. Philosophy of Information. Elsevier Science Publishers, Amsterdam, pp 693-719

45. Pieskä S, Kaarela J, Saukko O (2012) Towards easier human-robot interaction to help inexperiences operators in SMEs. In: Proceedings of the $3^{\text {rd }}$ IEEE International Conference on Cognitive Infocommunications (CogInfoCom2012). Kosice, pp 333-338

46. Kidd P (1992) Organisation, people and technology in European manufacturing. CEC - FAST, Final Report, Brussels

47. Krings B-J (2008) Global restructuring and its effects on occupations: Towards a new division of labor? In: Anderl R, Arich-Gerz B, Schmiede R (eds) Technologies of globalization. Proc Int Conf DFG Graduate School "Topology of Technology" of TU Darmstadt, Darmstadt, pp $117-129$

48. Moniz AB (2013) Robots and humans as co-workers? The human-centred perspective of work with autonomous systems, IET Working Papers Series 03/2013. http://ideas. repec.org/p/ieu/wpaper/51.html

49. Taylor RH (ed) (1996) Computer-integrated surgery, technology and clinical application. MIT Press, Cambridge, MA

50. Speich J, Rosen J (2004) Medical robotics. In: Wnek G, Bowlin G (eds) Encyclopedia of biomaterials and biomedical engineering. Marcel Dekker, New York, pp 983-993

51. Schmiede R (1980) Rationalisierung und reelle Subsumption. Leviathan 8(4):472-497
52. Acemoglu D, Restrepo P (2019) Automation and new tasks: How technology displaces and reinstates labor. IZA Discussion Paper Series 12293 (April)

53. Autor DH, Levy F, Murnane RJ (2003) The skill content of recent technological change: An empirical exploration. Q J Econ 118(4):1279-1333

54. Greenan N, Kocoglu Y, Walkowiak E, Csizmadia P, Makó C (2009) The role of technology in value chain restructuring. KU Leuven, Leuven

55. International Federation of Robotics-IFR (2018) Executive summary World Robotics 2018 Industrial Robots. IFR

56. International Federation of Robotics-IFR and Metra MARTECH (2011) Positive impact of industrial robots on employment. IFR/MetraMARTECH, London

57. Krings B-J (2013) Arbeit und Technik. In: Grunwald A (ed) Handbuch Technikethik. Metzler, Stuttgart, pp 217-222

58. Lutz B (1987) Das Ende des Technikdeterminismus und die Folgen. In: Lutz B (ed) Technik und sozialer Wandel. Verhandlungen des 23. Deutschen Soziologentages, Frankfurt a.M., pp 34-57

59. Pfeiffer S (2016) Robots, Industry 4.0 and humans, or why assembly work is more than routine work. Societies 6. https://doi.org/10.3390/soc6020016

60. Gallie D, Zhou Y (2013) Work organization and employee involvement in Europe. European Foundation for Improvement of Living and Working Conditions, Dublin

61. Clegg CW, Corbett M (1987) Research and development into 'humanizing' advanced manufacturing technology. In: Clegg CW, Kemp NJ (eds) Wall TD. The human side of advanced manufacturing technology. John Wiley \& Sons, Chichester

62. Brödner P (1988) Options for CIM: 'Unmanned factory' versus skill-based manufacturing. Compu Integr Manuf Syst 1(2):67-74

63. National Robotics Initiative (2013) Roadmap for U.S. robotics from internet to robotics. National Science Foundation, Arlington

64. National Robotics Initiative (2016) Roadmap for U.S. robotics from internet to robotics. National Science Foundation. https://cra.org/ccc/wp-content/uploads/sites/2/ 2016/11/roadmap3-final-rs-1.pdf

65. Lösch A, Grunwald A, Meister M, Schulz-Schaeffer I (eds) (2019) Socio-technical futures shaping the present: Empirical examples and analytical challenges. Springer VS, Wiesbaden

66. De Santis et al (2008) An atlas of physical human-robot interaction. Mech Mach Theory 43:253-270

67. ECS (2011a) Robots and robotic devices - Safety requirements for industrial robots. Part 1: Robots (EN ISO 10218-1:2011). European Committee for Standardization

68. ECS (2011b) Robots and robotic devices - Safety requirements for industrial robots. Part 2: Robot systems and integration (EN ISO 10218-2:2011). European Committee for Standardization

69. Sadeghian H, Herfst R, Dekker B, Winters J, Bijnagte T, Rijnbeek R (2017) High-throughput atomic force microscopes operating in parallel. Rev Sci Instrum 88:033703

70. Bensaúde-Vincent B (2010) Objects in nanotechnology. In: Fiedeler U, Coenen C, Davies S, Ferrari A (eds) 
Understanding nanotechnology: Philosophy, policy and publics. AKA/IOS Press, Heidelberg, pp 9-21

71. Khare HS, Gosvami NN, Lahouij I, Milne ZB, McClimon JB, Carpick RW (2018) Nanotribological printing: A nanoscale additive manufacturing method. Nano Lett 18:6756-6763

72. Bogue R (2010) Microrobots and nanorobots: A review of recent developments. Industrial Robot: An International Journal 37(4):341-346

73. Ru C, Zhang Y, Sun Y, Zhong Y, Sun X, Hoyle D, Cotton I (2010) Automated four-point probe measurement of nanowires inside a scanning electron microscope. IEEE Trans Nanotechnol 10(4):674-681. https://ieeexplore.iee.org/ document/5546976

74. Yang Z, Wang Y, Yang B, Li G, Chen T, Nakajima T, Sun L, Fukuda T (2016) Mechatronic development and vision feedback control of a nanorobotics manipulation system inside SEM for Nanodevice Assembly. Sensors 16:1479. https://doi.org/10.3390/s16091479

75. Requicha A et al (2003) Nanorobots, NEMS, and nanoassembly. Proc IEEE 91(11):1922-1933. http://ieeexplore.ieee.org/ lpdocs/epic03/wrapper.htm?arnumber $=1240080$

76. Bernstein D, Crowley K, Nourbakhsh I (2007) Working with a robot: Exploring relationship potential in humanrobot systems. Interact Stud 8(3):465-482

77. Moldaschl M (2010) Organisierung und Organisation von Arbeit. In: Böhle F, Voß GG, Wachtler G (eds) Handbuch Arbeitssoziologie. VS Verlag, Wiesbaden, pp 263-299

78. Madou MJ (2007) Fundamentals of microfabrication. CRC Press, New York

79. Krüger J, Lien TK, Verl A (2009) Cooperation of human and machines in assembly lines. CIRP Ann Manuf Technol 58:628-646

80. Lewis $\mathrm{M}$ et al (2011) Process and performance in humanrobot teams. J Cogn Eng Decis Mak 5(2):186-208

81. Morioka SS (2010) A new cell production assembly system with human-robot cooperation. CIRP Ann Manuf Technol 59(2010):9-12
82. EU Robotics (2014) Robotics 2020 Multi-Annual Roadmap for Robotics in Europe. Brussels

83. MAR (2017) Robotics 2020 Multi-Annual Roadmap for Robotics in Europe Horizon 2020 Call ICT-2017 (ICT25, ICT-27 \& ICT-28). European Commission/SPARC, Brussels

84. Abicht L, Freikamp H, Schumann U (2006) Identification of skill needs in nanotechnology. Cedefop Panorama series 120. Luxembourg

85. Lenz C et al (2008) Joint-action for humans and industrial robots for assembly tasks. In: Proceedings of $17^{\text {th }}$ IEEE International Symposium on Robot and Human Interactive Communication. Munich, pp 130-135

86. Greenfield A (2018) Radical technologies: The design of everyday life. Verso, London

87. Moniz AB, Krings B-J (2016) Robots working with humans or humans working with robots? Searching for social dimensions in new human-robot interaction in industry. Societies 6(3). https://doi.org/10.3390/soc6030023

88. Bethel C, Murphy RR (2010) Review of human studies methods in HRI and recommendations. International Journal of Social Robots 2:247-359

89. Bullinger H-J, Korndörfer V, Salvendy G (1987) Human aspects of robotic systems. In: Salvendy G (ed) Handbook of human factors. John Wiley, New York, pp 1657-1693

90. Stipancic T, Jerbic B, Curkovic P (2012) Context-aware system applied in industrial assembly environment. Int $\mathbf{J} \mathrm{Adv}$ Rob Syst 9(234):1-10

91. Moniz AB (2018) Robótica e trabalho. O futuro hoje. Glaciar/FLAD, Lisbon

Publisher's Note Springer Nature remains neutral with regard to jurisdictional claims in published maps and institutional affiliations. 